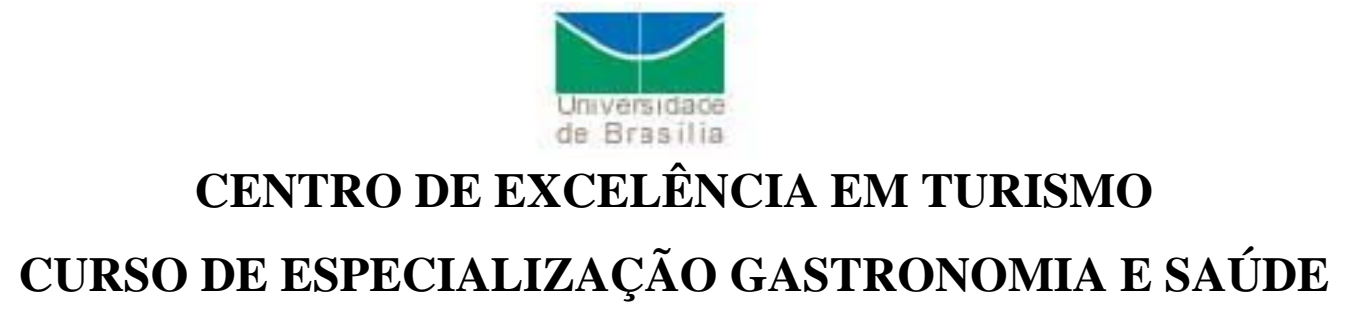

LAURA LADEIRA VENTURA DUMAS

ACEITABILIDADE DA REDUÇÃO DE SÓDIO EM UM RESTAURANTE DE TAGUATINGA NORTE

BRASÍLIA - DF 


\title{
ACEITABILIDADE DA REDUÇÃO DE SÓDIO EM UM RESTAURANTE DE TAGUATINGA NORTE
}

\begin{abstract}
Monografia apresentada ao centro de excelência em Turismo - UNB como requisito parcial para obtenção de título de especialista em Gastronomia e Saúde.

Orientadora: Prof. Doutora Raquel Botelho
\end{abstract}

BRASÍLIA - DF

2008 
Ficha Catalográfica

DUMAS, L. V. Laura

ACEITABILIDADE DA REDUÇÃO DE SÓDIO EM UM RESTAURANTE DE TAGUATINGA NORTE

Monografia do curso Especialização em Gastronomia e Saúde - Universidade de Brasília. Centro de Excelência em Turismo. Brasília, 2008.

Área de concentração - Nutrição

Orientação - Raquel Botelho

1.Hipertensão Arterial. Redução de Sódio. Ficha Técnica de preparação 


\section{ACEITABILIDADE DA REDUÇÃO DE SÓDIO EM UM RESTAURANTE DE TAGUATINGA NORTE}

Monografia apresentada ao Centro de Excelência em Turismo - CET, da Universidade de Brasília, como requisito parcial à obtenção do grau de Especialista em Gastronomia e Saúde.

Aprovado em:

Prof. (a)Dra Raquel Assunção Botelho

Banca examinadora

Prof. (a)

Prof. (a)

BRASÍLIA - DF

2008 


\section{AGRADECIMENTOS}

Agradeço, primeiramente, a Deus por ter me dado forças e paciência para não desanimar. Ao meu amigo Vitor e seus funcionários pela paciência e apoio para comigo, por ter permitido que eu realizasse a pesquisa em seu restaurante.

À minha irmã, pela orientação e incentivo e a minha mãe, por sempre acreditar em mim nas horas mais difíceis ao longo da minha caminhada acadêmica.

À professora e Dra. Raquel Botelho, pela paciência e dedicação e à Professora Verônica, por ter contribuído indiretamente pela composição do trabalho. 
SUMÁRIO

1. INTRODUÇÃO 10

2. OBJETIVOS 12

3. MATERIAIS E MÉTODOS 13

3.1. Avaliação das Porções 14

4. REVISÃO BIBLIOGRÁFICA

4.1. HIPERTENSÃO - DEFINIÇÃO E FATORES DE RISCO

4.2. TIPOS DE HIPERTENSÃO

4.3. PREVALÊNCIA 18

4.4. TRATAMENTO 18

4.4.1. Tratamento Não-Farmacológico 18

4.4.1.1 Tratamento Nutricional $\quad 19$

4.4.2. Tratamento Farmacológico 20

5. INGESTÃO DE SÓDIO 21

5.1. FICHA TÉCNICA DE PREPARAÇÃO 23

5.2. SUBSTITUTOS DO SAL 24

6. RESULTADOS E DISCUSSÃO 25

7. CONCLUSÃO 35

ANEXOS 36

BIBLIOGRAFIA $\quad 47$ 


\section{LISTA DE QUADROS E TABELAS}

Quadro 1 - Classificação da HAS de acordo com a etiologia 16

Quadro 2 - Classificação da HAS de acordo com o nível de pressão sistólica e 17 diastólica

Quadro 3 - Teor de sódio de alguns alimentos por 100g 22

Quadro 4 - Algumas utilizações das ervas 25

Quadro 5 - Algumas ervas e suas substâncias bioativas 26

Tabela 1 - Composição Nutricional das preparações 28

Tabela 2 - Composição Nutricional das amostras de Feijão Tropeiro 29

Tabela 3 - Composição Nutricional das amostras de Farofa com Ovos 29

Tabela 4 - Quibe assado recheado com molho branco 30

Tabela 5 - Médias de aceitação da farofa com ovos 31

Tabela 6 - Médias de aceitação do Feijão Tropeiro 31

Tabela 7 - Médias de aceitação do Quibe Assado 32

Tabela 8 - Percentual de aceitação da farofa com ovos 32

Tabela 9 - Percentual de aceitação do feijão tropeiro 33

Tabela 10 - Percentual de aceitação do quibe assado 33

Tabela 11- Percentual de redução de sódio de cada preparação 33 


\section{LISTA DE ANEXOS}

Anexo 1 - Modelo da Ficha Técnica de Preparação 33

$\begin{array}{ll}\text { Anexo } 2 \text { - Modelo de análise sensorial } & 38\end{array}$

Anexo 3 - Ficha técnica do feijão tropeiro - original. 39

Anexo 4 - Ficha de preparação de Quibe assado com molho branco - original 40

Anexo 5 - Ficha técnica da farofa com ovos - original 42

Anexo 6 - Ficha técnica do quibe assado recheado com molho branco - modificado 43

Anexo 7 - Ficha técnica do feijão tropeiro - modificado 45

Anexo 8 - Ficha técnica da farofa de ovos - modificada 46 


\section{RESUMO}

A hipertensão arterial sistêmica (HAS) é uma doença crônica não transmissível de etiologia multifatorial, sendo a causa mais importante de redução da qualidade de vida e da expectativa de vida. É responsável por complicações cardiovasculares, coronarianas, renais, encefálicas entre outas. Seu controle tem se tornado um desafio para os profissionais, visto que seu tratamento exige a participação ativa do paciente no sentido de mudar seus hábitos alimentares, onde se consome uma alimentação rica em grandes quantidades de alimentos de origem animal, gordura, açúcares e alimentos industrializados, contribuindo para o aparecimento das doenças crônica não transmissível, entre elas a hipertensão. Assim sendo, é de fundamental importância a redução do consumo de sódio da alimentação. Com o objetivo de fazer com que as pessoas que se alimentam fora do lar se habituem com uma refeição com menos sódio, a presente pesquisa, realizada em um restaurante de Taguatinga Norte, visa analisar a aceitabilidade dos comensais de uma Unidade de Alimentação e Nutrição (UAN) de preparações com redução de sódio. A partir do cálculo das Fichas Técnicas de preparação das receitas escolhidas (feijão tropeiro, farofa e quibe assado recheado com molho branco) foram feitas modificações em cada preparação para que cada porção atingisse $200 \mathrm{mg}$ de sódio e, posteriormente, feita a comparação sensorial com as receitas originais. Após ter aplicado um teste de analise sensorial com as receitas originais e as modificadas, notou-se que a modificação do feijão tropeiro foi a preparação mais aceita entre as pessoas que participaram da pesquisa por ter sido compensado o sal com mais cebola e cebolinha melhorando seu sabor e sua aparência ao acrescentar mais couve. Nesse estudo, a ausência do sal não foi notada pelos clientes, pois essa retirada foi feita de forma gradual. Para que as pessoas se acostumem com a ausência do sódio, é precioso retirá-lo gradualmente ou trocá-lo por ervas ou especiarias.

Palavras chaves: hipertensão arterial, redução, sódio, ficha técnica de preparação. 


\begin{abstract}
The sistemical arterial hipertension is not transmissible a chronic illness of multifactorial etiology that compromises the sanguineous vases of the organism. Treated $\mathrm{E}$ being precociously cannot unchain other illnesses as: renal commitment, cerebral vascular accident, among other. Its control involves change of the alimentary standard of the people, where if it consumes a rich feeding in great amounts of foods of animal origin, industrialized fat, sugars and foods, contributing for the appearance of the illnesses chronic not transmissible, between them the hipertension. Thus being of basic importance the reduction of the sodium consumption of the feeding. With the objective to make with that the people whom if they outside feed of the home if accustom if to feed with a meal with little sodium, the present research carried through in a restaurant of Taguatinga North aims at to analyze the acceptability of the comensais of a UAN of preparations with sodium reduction. From it I calculate of the Fiches Techniques of preparation of chosen prescriptions (tropeiro beans, farofa and quibe baked stuffed with white gravy) had been made modifications in each preparation so that each portion reached $200 \mathrm{mg}$ of sodium and later made the comparison with original prescriptions. After to have applied a test of analyzes sensorial with original prescriptions and the modified ones noticed that the modification of the tropeiro beans was the preparation most accepted between the people who will participate of the research for having been compensated the salt with more onion and chive improving its flavor and its appearance when adding more borecole.
\end{abstract}

Palavras chaves: arterial hipertension, reduction, sodium, fiche preparation technique. 


\section{INTRODUÇÃO}

A hipertensão arterial sistêmica (HAS) é uma doença crônica não transmissível, de etiologia multifatorial que compromete os vasos sanguíneos do organismo. Não sendo tratada precocemente pode desencadear complicações como: comprometimento renal, acidente vascular cerebral, entre outras (AMODEO, 2006). Além disso, é um importante problema de saúde pública comum nos países desenvolvidos, sendo considerada um "mal silencioso" porque nem todas as pessoas hipertensas apresentam sintomas (KRAUSE, 2005).

Seu controle é um desafio para os profissionais de saúde, pois seu tratamento exige uma participação ativa do paciente, no sentido de modificar alguns comportamentos prejudiciais à sua própria saúde (CADE, 2001).

Entre os fatores de risco que levam a um aumento da HAS estão: obesidade, estresse, idade, sedentarismo, raça e fatores dietéticos, como ingestão de sódio, potássio e cálcio (SANTOS, 2005).

Considerando que os padrões da dieta e do estilo de vida encontra-se em processo de estruturação e discussão na sociedade moderna, a implantação de possíveis estratégias educativas e intervencionistas, incorporando a verificação da pressão arterial na infância nos cuidados básicos de saúde, possibilitará o diagnóstico e o tratamento da hipertensão arterial e de seus fatores de risco precocemente (SALGADO; CARVALHÃES, 2003; LINO et al., 2004 OLIVEIRA et al., 2004)

A prevenção da hipertensão arterial requer além de mudança de estilo de vida, mudanças de hábitos alimentares, evitando o consumo de alguns alimentos processados, como enlatados, embutidos, alimentos em conserva, temperos prontos, produtos industrializados em geral, que contém altas quantidades de sódio - cerca de até 20 vezes mais sal do que o produto natural (COUTINHO, 2002) - e não adicionar sal aos alimentos já preparados.

O tratamento da hipertensão arterial envolve ações, tais como o uso de medicação antihipertensiva de forma regular, controle do peso, ingestão de dieta hipossódica com teor adequado de gordura saturada e colesterol e a prática de exercícios físicos, pois estas colaboram com a redução da pressão arterial e alguns pacientes minimizam as complicações que possam vir a aparecer (CADE, 2001). No âmbito nutricional, utiliza-se também a adição do sal de ervas - mistura em proporções iguais de temperos desidratados - para substituir o sal comum na preparação dos pratos, além de usar ervas frescas no lugar do sal e condimentos 
naturais que acentuam o sabor (limão, alho, cebola etc...) com objetivo de obter uma melhor adesão ao tratamento (BRASIL, 2006).

Mudanças no padrão alimentar da população, onde as pessoas têm como base da dieta um consumo de grandes quantidades de alimentos de origem animal, gordura, açúcares e alimentos industrializados, contribuem para o aparecimento de doenças crônicas não transmissíveis, entre elas a hipertensão. Além disso, nos dias atuais, as mulheres estão cada dia mais participando da população economicamente ativa e com isso, as pessoas comem cada vez mais fora do lar, optando por comidas rápidas e práticas que geralmente são mais difíceis de controlar o teor de sal consumido.

A recomendação do consumo de sal é de 5 a 6 gramas por dia, o equivalente a 1 colher de chá rasa. Em geral, o brasileiro consome o dobro da recomendação. Já para pessoas hipertensas, esta recomendação reduz para 4 gramas de sal por dia, ou 2 colherinhas de café. Estes chegam a consumir 17,4 gramas dia (BRASIL, 2006).

Com esse consumo excessivo e com o desconhecimento de como a alimentação fora do lar está comprometendo esse consumo, há uma grande preocupação dos nutricionistas no controle das refeições servidas fora do lar. Para que esse controle ocorra, esses profissionais devem fazer uso das fichas técnicas de preparação, instrumento gerencial e de controle que possibilita a avaliação de cada receita e modificação, quando necessária, para adequar o teor nutricional das refeições servidas (AKUTSU et al, 2005). É uma das formas intervencionistas que as Unidades de Alimentação e Nutrição possuem para auxiliar na prevenção da hipertensão arterial na população. 


\section{OBJETIVOS}

\subsection{OBJETIVO GERAL}

- Analisar a aceitabilidade dos clientes de uma UAN de preparações com redução de sódio.

\subsection{OBJETIVOS ESPECÍFICOS}

- Desenvolver as fichas técnicas de preparação (FTP) das preparações escolhidas para modificação no teor de sódio.

- Calculo das FTP das preparações escolhidas.

- Avaliar a quantidade de sódio das preparações.

- Modificar as preparações pré-estabelecidas

- Avaliar a aceitabilidade das preparações originais e modificadas. 


\section{MATERIAIS E MÉTODOS}

O estudo de caráter transversal e exploratório foi realizado em um restaurante de Taguatinga Norte, Distrito Federal. O estudo foi dividido em 6 etapas: revisão de literatura, escolha das preparações, determinação das porções e elaboração das FTPs, cálculo e avaliação das FTPs, modificação das receitas com excesso de sódio, avaliação da aceitabilidade pela clientela.

Foram analisados livros e artigos em língua portuguesa publicados em revistas e jornais e indexados pela base de dados LILAC'S e GOOGLE ACADÊMICO, entre o período de fevereiro a março de 2008. Nas bases de dados foram localizados artigos a partir das seguintes palavras chaves: hipertensão arterial, redução, sódio, ficha técnica de preparação.

Foi avaliado o cardápio do restaurante, objeto deste estudo, e escolhidos por conveniência 3 pratos (feijão tropeiro, farofa de ovos e quibe assado recheado com molho branco), em função da freqüência de oferta semanal, do conteúdo de sódio das preparações escolhidas e a aceitabilidade das preparações pelos comensais relatada pelo proprietário do restaurante.

Solicitou-se a autorização através de um documento preenchido pelo proprietário do estabelecimento para que a produção de cada uma das preparações fosse acompanhada e a FTP, de acordo com o modelo proposto por Botelho e Camargo (2005) (anexo 1), fosse elaborada.

Após a elaboração de cada uma das fichas (Anexos 2, 3 e 4), os ingredientes foram calculadas utilizando-se a Tabela Brasileira de Composição (TACO, 2006). Com os cálculos de sódio de cada uma das preparações, procedeu-se a avaliação de cada uma delas mediante as recomendações de sódio do Ministério da Saúde de $2000 \mathrm{mg}$ de sódio por dia. Para a avaliação de cada preparação, utilizou-se a recomendação de que o almoço deve contribuir com 35 a 40\% dos nutrientes de uma dieta (Brasil, 2006). Dessa forma, o almoço do estabelecimento pode oferecer de 700 a $800 \mathrm{mg}$ de sódio a cada um dos seus clientes. Como o almoço deve ser composto por prato principal, guarnição, entradas e acompanhamentos, inferiu-se nesse trabalho que cada uma das preparações deveria ter no máximo $200 \mathrm{mg}$ de sódio por porção. 


\subsection{DETERMINAÇÃO DAS PORÇÕES}

Nesta etapa, foi observado o consumo de 20 clientes para cada preparação seguindo a metodologia de Sávio (2002).

Como o restaurante apresenta apenas o fluxo de 100 clientes, optou-se por avaliar $20 \%$ da clientela em função de que esses mesmos clientes foram convidados para a aplicação do teste de aceitabilidade das preparações havendo algumas recusas por estarem com presa e por falta de disponibilidade de tempo.

Foi aplicado um teste de análise sensorial com escala hedônica de 7 pontos (anexo5) em 20 clientes em dias em que foi servidas as preparações, no qual avaliaram os três pratos escolhidos antes da modificação das receitas e, posteriormente, as mesmas preparações com redução em sódio. Os clientes avaliaram os quesitos: sabor, cor, odor e aceitabilidade. Participaram da pesquisa, apenas os clientes que se servissem com as preparações escolhidas. Em seguida, foram reproduzidas as receitas modificadas no restaurante pelo cozinheiro sob supervisão.

Foi feita a avaliação dos resultados comparando antes e depois usando o teste $\mathrm{T}$ para estatística. A partir dos testes aplicados, foi calculado a média das categorias analisadas (sabor, odor e avaliação geral do produto) e o percentual de aceitação para averiguar se os pratos reduzidos foram bem aceitos ou não pela amostra. 


\section{REVISÃO BIBLIOGRÁFICA}

\subsection{HIPERTENSÃO - DEFINIÇÃO E FATORES DE RISCO}

Hipertensão arterial é uma doença cardiovascular determinada pela força e pelo volume com que o coração impulsiona o sangue pelos vasos sangüíneo para circular por todo corpo. É expressa pela pressão sanguínea sistólica, que é a pressão mais alta medida durante um ciclo cardíaco e pela pressão diastólica, que é a pressão arterial mais baixa exercida durante o relaxamento do coração (GUYTON; HALL, 2002).

É considerado um "mal silencioso", pois muitas pessoas com hipertensão podem ser assintomáticas por anos e por isso levar a desenvolver problemas cerebrais, renais e cardiovasculares (KRAUSE, 2005). É uma doença crônica não transmissível de etiologia multifatorial, que compromete os vasos do organismo, determinando alteração no tônus vasomotor e favorecendo a vasoconstrição, fato que leva ao aumento da pressão arterial (AMODEO, 2006).

Segundo o III Consenso Brasileiro de Hipertensão Arterial (CBHA, 1998), o hipertenso é todo indivíduo adulto, maior de 18 anos com valores de pressão arterial sistólica igual ou maior do que $130 \mathrm{mmHg}$ ou com a pressão diastólica igual ou superior a $85 \mathrm{mmHg}$ em pelo menos duas aferições realizadas em ocasiões diferentes.

De acordo com a Sociedade Brasileira de Hipertensão, 2000 a prevalência da hipertensão arterial na população adulta é elevada, em torno de 15 a $20 \%$ da população brasileira. Sendo essa patologia considerada como um dos principais fatores de riscos para o desenvolvimento de doenças cardiovasculares, tornando-se epidemiológica e clinicamente importante (SILVA, 2005).

Há evidências de que a hipertensão arterial pode ter seu início na infância ou adolescência (SANTOS, 2005). É determinada pela interação entre fatores genéticos e ambientais. Entre os fatores de riscos associados aos níveis mais elevados de pressão arterial estão: obesidade, estresse, estado socioeconômico, idade, sexo, raça, freqüência cardíaca, fatores genéticos, alterações ambientais e fatores dietéticos - presença de sódio, potássio e cálcio - (SANTOS, 2005). O excesso de peso está associado ao aumento da HAS, Os hipertensos obesos devem reduzir o peso, de modo a alcançar um IMC inferior a $25 \mathrm{~kg} / \mathrm{m}^{2}$ e Relação Cintura-Quadril (RCQ) inferior a 0,8 para as mulheres e a 0,9 para os homens, em razão de sua associação com o desenvolvimento de doenças cardiovasculares (III CBHA, 1998). A identificação dos fatores de risco propicia uma oportunidade para que se possa 
intervir precocemente possível em uma seqüência de eventos sabidamente associados com significativa morbidade e mortalidade em adultos (GARCIA, 2006).

A combinação de diversos fatores de risco exerce um efeito deletério sobre o sistema cardiovascular e a atenção para a identificação e a intervenção precoce sobre eles poderia prevenir ou retardar o desenvolvimento das complicações associadas com a pressão arterial (MAGALHÃES, 2002).

Os valores limites para pressão arterial ainda são assunto de discussão, pois variam muito de acordo com o sexo, idade, e raça. Em adultos, é estabelecido como 14 X $90 \mathrm{mmHg}$ (MIGUEL, 2006).

\subsection{TIPOS DE HIPERTENSÃO}

A Hipertensão arterial pode ser classificada de acordo com:

Quadro 1 - Classificação da HAS de acordo com a etiologia

\begin{tabular}{|l|l|}
\hline \multicolumn{1}{|c|}{ Classificação } & Caracterização \\
\hline Primária & - Corresponde à cerca de 95\% dos \\
& casos. Família \\
- & Causa desconhecida \\
- & Presença de predisposição genética \\
& (AMODEO, 2006). \\
\hline Secundária & Corresponde a apenas 5\% dos casos. \\
- Causas definidas: & nefropatias, \\
diabetes, a apnéia obstrutiva do sono, \\
os tumores de glândulas supra-renais \\
e a estenose das artérias renais \\
(AMODEO, 2006).
\end{tabular}


Quadro 2 - Classificação da HAS de acordo com o nível de pressão sistólica e diastólica

\begin{tabular}{|c|c|}
\hline Classificação & Caracterização \\
\hline Hipertensão leve & 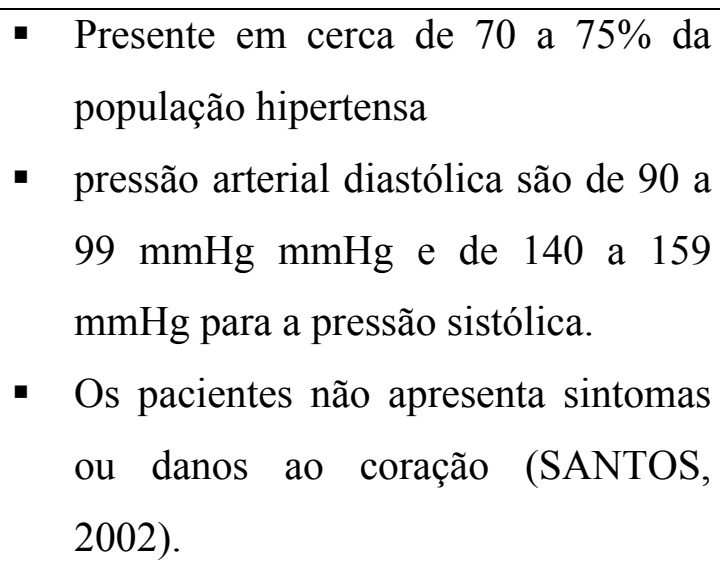 \\
\hline Hipertensão moderada & $\begin{array}{l}\text { - Pressão diastólica de } 100 \text { a } \\
109 \mathrm{mmHg} \text { e de } 160 \text { a } 179 \mathrm{mmHg} \text { para } \\
\text { a pressão sistólica } \\
\text { - Os pacientes talvez não apresentem } \\
\text { sintomas ou apenas sintomas } \\
\text { ocasionais relacionados com } \\
\text { complicações da hipertensão como } \\
\text { respiração curta, dores no peito, } \\
\text { fraqueza muscular, visão turva etc. } \\
\text { (MADIAS, 1982). }\end{array}$ \\
\hline Hipertensão grave ou severa & $\begin{array}{l}\text { - Pressão diastólica igual ou acima de } \\
110 \mathrm{mmHg} \text { sistólica igual ou acima de } \\
180 \mathrm{mmHg} \text {. } \\
\text { - Pacientes estão em situação de crise, } \\
\text { devendo ser considerado um caso } \\
\text { agudo de emergência médica. Em } \\
\text { geral, está associada a colapsos } \\
\text { cardíacos, renais e sinais graves de } \\
\text { danos ao sistema nervoso central } \\
\text { (MADIAS, 1982; SANTOS, 2002). }\end{array}$ \\
\hline
\end{tabular}




\subsection{PREVALÊNCIA}

A HAS é uma doença de ala prevalência no Brasil, atingindo os adultos jovens e os idosos em aproximadamente $20 \%$ e $50 \%$ respectivamente, sendo responsável por $80 \%$ dos casos de acidente vascular cerebral, $60 \%$ dos casos de infarto agudo do miocárdio, $40 \%$ as aposentadorias precoces, além de significar um custo de 475 milhões de reais gastos com 1,1 milhões de internação por ano (CASTRO, 2005; ZAITUNE, 2006).

\subsection{TRATAMENTO}

Por se tratar de uma doença multifatorial, o tratamento envolve a participação de vários profissionais de saúde, promovendo ações educativas com ênfase na mudança de estilo de vida, na correção e identificação de fatores de risco presentes que possam agravar o caso (III CBHAS, 1998).

É de grande importância que o profissional de saúde, ao abordar o hipertenso, atente as percepções do paciente para que ele venha conhecer sua doença, a desenvolver autoresponsabilidade, a assumir seu papel ativo, a modificar seu comportamento em relação à saúde e a manter sentimentos positivos (CASTRO, 2005).

\subsubsection{Tratamento Não-Farmacológico}

O tratamento não-farmacológico tem por objetivo reduzir a morbidade e a mortalidade por meio de mudanças no estilo de vida que favoreçam a redução da pressão arterial e está indicado a todos os hipertensos e aos indivíduos mesmo que normotensos, mas de alto risco cardiovascular (CHAVES JR et al., 1998).

Dentre as mudanças no estilo de vida do hipertenso estão: redução de peso corporal; dieta hipossódica e balanceada, que atenda às necessidades individuais; alta ingestão de frutas e hortaliças; redução do consumo de bebida alcoólica e realização regular de exercícios físicos, diminuição do tabagismo e a substituição gordura saturada (gordura animal) pela gordura poliinsaturada e monoinsaturada, sendo efetiva no tratamento e devendo ser indicada antes ou conjuntamente com a terapia farmacológica (CASTRO, 2005; DALTEPIANE, 2007). 


\subsubsection{Tratamento Nutricional}

O tratamento nutricional visa não apenas à redução dos níveis da pressão arterial, mas também a incorporação de hábitos alimentares permanentes e age em conjunto ao tratamento não-farmacológico e farmacológico (CUPPARI, 2005).

A nutrição exerce papel fundamental no tratamento do hipertenso, na realização de avaliação nutricional e identificação de hábitos alimentares anteriores, na prescrição de dietas, sempre considerando os aspectos socioeconômicos e culturais individuais, na promoção da educação nutricional individual e em grupos e na implantação do conceito de alimentação saudável, apresentando sugestões de receitas práticas e saborosas, preparadas de acordo com as limitações do paciente hipertenso (MACHADO et al., 1998).

Na consulta periódica de nutrição, cabe ao nutricionista fazer uma avaliação dietética, incluindo consumo diário de sal, bebidas alcoólicas, gordura saturada, cafeína e ingestão de fibras, frutas e vegetais além de obter as medidas antropométricas (peso, estatura, IMC, circunferência do quadril e da cintura) e solicitar exames bioquímicos (potássio plasmático, creatinina plasmática, glicemia de jejum, colesterol total, triglicérides plasmáticos e ácido úrico plasmático) para o acompanhamento (V DIRETRIZES BRASILEIRAS DE HIPERTENSÃO, 2006).

Sempre respeitando a individualidade de cada paciente, o nutricionista apresenta dicas importantes para que haja um melhor resultado no seu tratamento como: ler os rótulos cuidadosamente, ingerir 2 litros de água ao longo do dia, evitar preparações instantâneas, comer peixe de duas a três vezes por semana, realçar o sabor de suas receitas usando ervas e especiarias, suco de limão, vinho ou vinagre, escolher carnes cozidas, sempre evitando milanesas, churrasco ou carnes com molhos à base de maionese, evitar alimentos processados e preparados, pois eles contêm grande quantidade de sal (ex: caldo de carne, maionese, ketchup, massa de tomate, sopa pronta, salgadinhos, carne seca etc.), preferir os alimentos frescos (CUPPARI, 2005).

Dietas com alto teor de potássio, também são utilizadas no tratamento da hipertensão. O potássio induz à queda de pressão por ter um efeito anti-hipertensivo e exercer uma ação protetora contra danos cardiovasculares, sendo estratégia conjunta aos pacientes que fazem uso de diuréticos. Alguns alimentos ricos em potássio são: ervilha fresca, feijão, aveia, germe de trigo, rabanete, cará, salsa, almeirão, melão, maracujá, cereja crua, entre outros (CUPPARI, 2005). 
Uma estratégia ultimamente adotada pelos nutricionistas é a nova Dieta Darsh, que tem por objetivo prevenir o desenvolvimento da hipertensão. Foi desenvolvida a partir de um estudo norte americano, que se baseia numa alimentação rica em frutas, hortaliças, proteínas, lacticínios, potássio, magnésio, baixo teor de gordura saturada e colesterol, além de ter um consumo diário de $1500 \mathrm{mg}$ de sódio, sendo que a recomendação para a população brasileira em geral é de 2000mg (MINISTÉRIO DA SAÚDE, 2005). Não está explicado totalmente o seu mecanismo de ação, mas acredita-se que a combinação dos alimentos presentes nela seja responsável pela redução da pressão arterial (SAMPAIO; SABRY, 2007).

Neste plano alimentar, os pacientes são submetidos a uma redução da ingestão de sódio diário, incluindo também a ingestão grãos integrais, peixe, frango e nozes além de conter menos carne vermelha magra, doces, açúcar adicionado e refrigerantes. Ela é rica em potássio, magnésio e cálcio, assim como proteínas e fibras, sempre com objetivo de redução dos níveis da pressão sanguínea.

\subsubsection{Tratamento Farmacológico}

O tratamento farmacológico tem por objetivo básico reduzir a taxa de morbimortalidade por doenças cardiovasculares associados à elevação da pressão arterial e deve ser usado juntamente com o tratamento não farmacológico (SANTOS, 2002).

Dentre os medicamentos anti-hipertensivos mais utilizados estão os diuréticos, $\beta$ bloqueadores, antagonistas de cálcio e inibidores adrenérgicos (KRAUSE, 2005). Alguns destes medicamentos estimulam a excreção de sal e água pelos rins, atuam por meio do sistema nervoso para reduzir a resistência ao fluxo sanguíneo nos vasos e reduzir a atividade do coração (MADIAS, 1982). 


\section{INGESTÃO DE SÓDIO}

A ingestão de sódio não é suficiente para a instalação da hipertensão, pois nem todas as pessoas que consomem um alto teor do sódio são sensíveis ao sódio que é mais evidente em obesos e em pessoas com história familiar de hipertensão (KRAUSE, 2005).

O sódio e o potássio são minerais essenciais para a regulação dos fluidos intra e extracelulares, atuando na manutenção da pressão sanguínea. O sal de cozinha - cloreto de sódio - é a principal fonte de sódio, sendo composto por $40 \%$ desse elemento químico. A necessidade humana diária de sal é de cerca de 300-500 miligramas. A maior parte dos indivíduos, mesmo crianças, consome níveis além das suas necessidades. O consumo populacional excessivo, maior que $6 \mathrm{~g}$ diárias de sal (2,4g de sódio), é uma causa importante da hipertensão arterial (KRAUSE, 2005). A redução moderada de sódio reduz a pressão sangüínea para indivíduos sódio-sensíveis, o mesmo não acontece com indivíduos resistentes ao sódio. Estima-se que aproximadamente 50 a $60 \%$ dos indivíduos hipertensos sejam sódios sensíveis (BÓS; DALTEPIANE, 2007), cujo efeito pode ser potencializado por dietas pobres em potássio (GALVÃO, 2002).

De acordo com a Pesquisa de Orçamento Familiar (POF-2002-2003), a aquisição de sal para consumo domiciliar per capita corresponde em média a 9,6 g/dia, como ainda existe o consumo de sal fora do domicílio, esta quantidade pode ser maior. O sal é um produto natural que confere sabor aos alimentos e ressalta o paladar de outros ingredientes, além de ter uma importante função bactericida, esses são alguns motivos que dificultam a retirada do excesso de sal da dieta (SILVA, 2003).

Ao reduzir o consumo de sal, as pessoas que consomem habitualmente alimentos salgados, logo percebem a diferença, pois consideram que a comida fica menos saborosa. As papilas gustativas para o sabor salgado podem levar em torno de 6 meses para se adaptar ao novo paladar (MINISTÉRIO DA SAÚDE, 2006).

A orientação nutricional para o paciente hipertenso preconiza o não consumo de alimentos com alto teor de sódio, como produtos processados, enlatados, embutidos conservas, molhos prontos, caldo de carne, bebidas isotônicas e queijos em geral, além de preparar as refeições com pouco sal e não utilizar saleiro à mesa (CUPPARI, 2005).

O consumo total de sódio pode ser considerado proveniente de três fontes: $75 \%$ de alimentos processados, 10\% de sódio intrínseco e 15\% de sal de adição (CUPPARI, 2005). 
O quadro abaixo apresenta o teor de sódio de alguns alimentos.

\section{Quadro 3 - Teor de sódio de alguns alimentos por 100g}

\begin{tabular}{|cc|}
\hline Alimentos (100g) & Teor de sódio (mg) \\
Abacate & 02 \\
Abacaxi & 0,3 \\
Bacalhau & 13585 \\
Banana maçã in natura & 0,3 \\
Carne de boi magra & 52 \\
Biscoito de água e sal & 0,2 \\
Cenoura & 0,2 \\
Espinafre (cru) & 79 \\
Farinha de soja & 6 \\
Feijão mulatinho & 2 \\
Leite de vaca (tipo C) & 64 \\
Margarina Vegetal c/sal & 78 \\
Ovo de galinha (clara) & 181 \\
Ovo de galinha (gema) & 45 \\
\hline
\end{tabular}

\section{Fonte: TACO}

Atualmente, as pessoas se alimentam cada vez mais fora do lar, e além de ser uma alimentação preparada com produtos processados, ainda pode conduzir à adição de sal pelo cliente no estabelecimento com maior facilidade já que os saleiros ficam sobre a mesa sempre à disposição do cliente, podendo ele perder o controle nessa adição. Para que não se perca o controle do consumo de sal, o nutricionista deve conhecer cada preparação servida, a fim de se controlar o uso de produtos com alto teor de sódio nas preparações. Assim, a Ficha Técnica de Preparação se faz necessária, bem como a supervisão constante do nutricionista para que a mesma seja corretamente seguida. 


\subsection{FICHA TÉCNICA DE PREPARAÇÃO}

Ficha Técnica de Preparação (FTP) é um documento que registra passo-a-passo o processo de produção de uma preparação (pré-preparo e preparo), tendo como função registrar e padronizar as quantidades de matéria-prima a ser utilizada na produção, reduzindo assim, os custos e o desperdício de matéria-prima, além de permitir controlar o valor calórico e nutrientes fornecidos, influenciando diretamente na saúde da população atendida.

A FTP é um instrumento fundamental em qualquer área de produção, quanto mais precisa for, mais fácil tende a ficar a administração de um negócio no setor de alimentação (LINS, 2005).

Divide-se basicamente em duas partes: a primeira é gerencial, onde identifica todos os custos de matéria-prima essencial para executar aquela preparação e a segunda parte é operacional, que identifica todas as etapas da produção do prato, além de exibir uma fotografia do prato montado (FONSECA, 2007), podendo sempre variar seu modelo de cozinha para cozinha, mas sempre contendo: per capita (quantidade de matéria prima a ser utilizada por pessoa), fator de correção e coç̧ão, composição nutricional, o número de porções e o rendimento da receita produzida e o tempo total de preparo.

A presença da FTP dinamiza a preparação diária, na medida em que, quando definida pela UAN, pode fornecer aos funcionários o material que facilite a execução padronizada das preparações (AKUTSU, et al., 2005).

Também possibilita ao profissional de nutrição um planejamento de cardápio eficaz e um maior controle dos pedidos de compras a serem feitas (LINS, 2005).

Conhecendo as preparações que estão sendo servidas em cada estabelecimento é possível verificar a quantidade de sódio que o funcionário está adicionando e também verificar quais as formas de melhorar seu preparo para atender as recomendações atuais de ingestão de sódio por dia. Assim, conhecendo o que se produz, é possível que a equipe possa testar novas formas de conferir sabor às preparações sem utilizar somente o sal como condimento. 


\subsection{SUBSTITUTOS DO SAL}

Embora não exista um substituto para salgar os alimentos, troca-se o sal por ervas aromáticas e condimentos secos ou frescos que acentuam o sabor dos pratos, além de conterem baixas calorias (GALANTE; MORAES; AMODEO, 2006).

Juntamente com a baixa ingestão de sódio da dieta, aumenta-se a ingestão de alimentos ricos em potássio por contribuir para um melhor controle da pressão arterial, diminuir a freqüência de acidente vascular cerebral, proteger o sistema vascular e retardar o aparecimento da arteriosclerose, além de exercer efeito anti-hipertensivo, ter ação protetora contra danos cardiovasculares e de ser uma medida auxiliar em paciente submetido a tratamento com diuréticos, desde que não existam contra-indicações (III CONSENSO DE HIPERTENSÃO, 1998).

É importante lembrar que cerca de 35\% dos hipertensos com uso de diurético têm uma redução nos níveis séricos de potássio, o que pode causar arritmias ventriculares severas, diminuição da tolerância à glicose com resistência à ação da insulina (LOTAIF et al., 1995).

Substitui-se o sal refinado dos pratos principalmente pelo sal light que é uma mistura de partes iguais e cloreto de sódio (50\%) e cloreto de potássio (50\%) a fim de se reduzir o teor de sódio das preparações. Junto aos dois sais é adicionado iodato de potássio para evitar doenças na glândula tiróide. O cloreto de potássio tem a característica de ficar menos tempo no organismo do que o cloreto de sódio, daí a sua vantagem em reter água no organismo por menos tempo (MEDEIROS, 2004). O cuidado do hipertenso é de não utilizar o dobro de sal light para que o sabor se assemelhe ao alimento original.

Nem sempre comida sem sal significa comida sem graça. Para que as preparações continuem saborosas, pode-se recorrer aos diversos temperos naturais existentes, como as ervas e as especiarias (FERNANDES, 2007).

As ervas são plantas utilizadas secas ou frescas como aromatizantes das quais aproveita-se as folhas, sementes e flores. Podem ser adicionadas em diversas preparações, decorando, modificando as aparências visuais e tornando os pratos mais temperados, atraentes e requintados.

Existem vários tipos de ervas como manjericão, louro, sálvia, manjerona, hortelã, entre outras. Já as especiarias são as partes aromáticas das plantas, podendo ser rebentos, frutos, bagas, raízes ou cascas como alho, cebola, baunilha, canela, anis, entre outras (FERNANDES, 2007). 
Em geral, as ervas aromáticas e as especiarias, além de terem baixas calorias, facilitam a digestão e, logo, a absorção dos alimentos pelo organismo, estimula a produção de saliva e de suco gástrico, abrindo assim o apetite (CUPPARI, 2005).

Ressalta-se que deve-se usá-las em pouca quantidade nas preparações, pois algumas têm um sabor característico, podendo camuflar o verdadeiro sabor do alimento (LIMA, 2007).

O quadro abaixo demonstra algumas utilizações das ervas:

\section{Quadro 4 - Algumas utilizações das ervas}

\begin{tabular}{|c|c|}
\hline Mar & $\begin{array}{l}\text { Muito utilizado em preparações italianas, principalmente em molhos de tomate. } \\
\text { Esta erva possui folhas verdes com aroma característico }\end{array}$ \\
\hline Ma & $\begin{array}{l}\text { É uma erva adocicada. Pode ser utilizada em pizzas, assados e molhos. Procure } \\
\text { acrescentar esta erva na hora de servir o prato }\end{array}$ \\
\hline Ho & $\begin{array}{l}\text { Suas folhas são arredondadas e muito perfumadas. Esta erva pode ser utilizada } \\
\text { em sucos, chás, saladas, molhos, bombons, vitaminas e cozidos, entre outras } \\
\text { preparações. }\end{array}$ \\
\hline Sálvia & $\begin{array}{l}\text { Pode ser encontrada fresca ou seca, podendo aromatizar carnes, aves, peixes, } \\
\text { vegetais, queijos e ovos. Procure não misturar com outras ervas, pois poderá } \\
\text { perder o seu aroma. }\end{array}$ \\
\hline Est & $\begin{array}{l}\text { Com folhas finas, é acrescentado a molhos, frangos, peixes, ovos, etc. Possui } \\
\text { sabor acentuado, devendo ser utilizado com moderação }\end{array}$ \\
\hline Sals & $\begin{array}{l}\text { Existem dois tipos, de folhas lisas e frisadas. As folhas lisas são muito } \\
\text { utilizadas para decorar pratos. Porém, ambas podem ser utilizadas em diversas } \\
\text { preparações, como molhos, saladas, farofas, cozidos, etc. }\end{array}$ \\
\hline Co & $\begin{array}{l}\text { ssui odor agradável, é muito utilizado em preparações com alimentos do } \\
\text { ar, como peixes, mariscos e camarões. }\end{array}$ \\
\hline Louro & $\begin{array}{l}\text { É encontrado fresco, seco e em pó. Usado com moderação, é um ótimo tempero } \\
\text { para feijões, ensopados, assados e carnes grelhadas. }\end{array}$ \\
\hline Alecrim & $\begin{array}{l}\text { Acrescenta-se em carnes, aves, peixes e massas. Suas folhas são de cor verde } \\
\text { escura. }\end{array}$ \\
\hline Tomilho & $\begin{array}{l}\text { Esta erva possui sabor picante, é encontrada fresca, seca ou em pó, pode-se } \\
\text { utilizar em carnes, sopas, peixes, queijos e ovos }\end{array}$ \\
\hline
\end{tabular}


Fonte: http://vilaequilibrio.vilamulher.com.br/materia/nutricao/53-ervas-aromaticas-um-toque-especialna-sua-comida.html

Além destes temperos e ervas, existem muitos outros, mas não basta apenas saber de sua existência, é preciso que o cozinheiro saiba também combiná-los de forma que se completem e se combinem, resultando num aroma e sabor que agrade o paladar dos comensais.

Certas ervas e especiarias contêm em sua composição, algumas substâncias bioativas, que quando incluídas na alimentação diária modulam processos metabólicos ou fisiológicos, que resulta na redução de alguns tipos de carcinomas e na manutenção da saúde (COSTA, 2003)

Dentre essas substâncias, destacam-se os compostos fenólicos que além de serem responsáveis pela cor, adstringência, aroma dos alimentos, possuem propriedades fisiopatológicas como: antialergênica, antiarteriogênica, antiinflamatória, antimicrobia nantitrombótica, cardioprotetiva e vasodilatadora, mas o principal efeito dos compostos fenólicos tem sido atribuído à sua ação antioxidante que desempenha um papel importante na redução da oxidação lipídica em tecidos vegetal e animal, e na alimentação humana, mantendo a qualidade dos alimentos, reduzindo o risco de desenvolver doenças cardiovasculares e as doenças causadas por radicais livres em excesso, além de atuar no controle ou prevenção das mesmas e de alguns cânceres (ANDREO, 2006; COSTA, 2003)

O quadro a seguir mostra algumas ervas e suas substâncias bioativas.

\section{Quadro 5 - Algumas ervas e suas substâncias bioativas}

\begin{tabular}{|l|l|l|}
\hline Alimentos funcionais & $\begin{array}{l}\text { Substâncias } \\
\text { bioativas }\end{array}$ & Efeitos \\
\hline $\begin{array}{l}\text { Azeite de oliva, berinjela, Ácido fenólico } \\
\text { brócolis, cenoura, chás, cítricos, } \\
\text { grãos, morango, pimenta, repolho, } \\
\text { salsinha verde, tomate e uva }\end{array}$ & $\begin{array}{l}\text { Aumenta a atividade enzimática e a } \\
\text { absorção de nutrientes. Inibe a a } \\
\text { formação de nitrosaminas. }\end{array}$ \\
\hline Frutas e verduras & Bioflavonóides & Apresenta uma atividade antioxidante \\
\hline Açafrão e cominho & Curcumina & $\begin{array}{l}\text { Protege contra os agentes } \\
\text { cancerígenos do cigarro. }\end{array}$ \\
\hline $\begin{array}{l}\text { Leguminosas feijão, } \\
\text { amendoim, ervilha, lentilha, grão- }\end{array}$ & Isoflavonas & $\begin{array}{l}\text { Reduz as enzimas carcinogênicas e } \\
\text { reduz os efeitos da menopausa }\end{array}$ \\
\hline
\end{tabular}




\begin{tabular}{|l|l|l|}
\hline de-bico, fava) & Isotiocianato & $\begin{array}{l}\text { Estimula a produção de enzimas } \\
\text { protetoras do organismo e inibe a ação } \\
\text { dos radicais livres. }\end{array}$ \\
\hline Rábano, mostarda e rabanete & Licopeno & $\begin{array}{l}\text { Pigmento com ação antioxidante, que } \\
\text { protege contra câncer de próstata. }\end{array}$ \\
\hline Tomate, goiaba e melancia & Monoterpenos & $\begin{array}{l}\text { Antioxidante e auxilia a atividade de } \\
\text { enzimas protetoras. }\end{array}$ \\
\hline Alho e cebola & $\begin{array}{l}\text { Sulfetos } \\
\text { alílicos }\end{array}$ & $\begin{array}{l}\text { Estimula o sistema imunológico, } \\
\text { reduz colesterol e triglicerídeo, além } \\
\text { de combater os radicais livres que em } \\
\text { excesso são cancerígenos e } \\
\text { hipertensivos. }\end{array}$ \\
\hline
\end{tabular}

Frisa-se que nenhum desses alimentos isoladamente pode ser usado para solucionar algum problema de saúde. Para obter o efeito desejado, eles devem fazer parte de uma dieta equilibrada e ajustada às necessidades de cada indivíduo. 


\section{RESULTADOS E DISCUSSÃO}

A partir das fichas técnicas desenvolvidas nos alimentos escolhidos (feijão tropeiro, quibe assado recheado com molho branco e farofa) no estabelecimento do estudo, obtiveramse os seguintes resultados de composição nutricional (Tabela 1).

Tabela 1 - Composição Nutricional das preparações

\begin{tabular}{l|ccc}
\hline & Feijão tropeiro (105g) & Quibe assado (70g) & Farofa (50g) \\
\hline VET (por porção) & 211,71 Kcal & 106,77 Kcal & 209,74 Kcal \\
\% PTN & 12,92 & 59,41 & 5,07 \\
\% CHO & 62,62 & 18,08 & 66,19 \\
\% LIP & 24,45 & 22,50 & 28,73 \\
\hline Na (mg) & $\mathbf{5 3 1 , 9 5}$ & $\mathbf{3 0 2 , 5 9}$ & $\mathbf{3 7 9 , 8 4}$ \\
\hline
\end{tabular}

Para a composição de macronutrientes, todas as preparações se mostraram adequadas, não havendo desequilíbrio de gordura. O prato principal, quibe assado, apresenta maior conteúdo protéico como necessário e o feijão tropeiro como acompanhamento e a farofa como guarnição, maior teor de carboidratos.

Em relação ao sódio, todas as preparações estão acima da recomendação estabelecida neste trabalho (200mg de sódio por porção), que foi determinada a partir da recomendação do Ministério da Saúde em que o almoço deve contribuir no máximo com 700 a 800mg de sódio. Como o almoço é composto por prato principal, guarnição, acompanhamento e salada, dividiu-se essa recomendação por 4 itens e assim, cada porção de cada um dos itens do cardápio deve contribuir, no máximo, com 200mg de sódio.

Dentre os 20 clientes observados, quatro indivíduos consumiram 2 porções de feijão tropeiro ou seja 1063,9 mg de sódio só com o acompanhamento. Isso representa metade da recomendação por porção sugerida neste trabalho. Cinco indivíduos avaliados consumiram 3 pedaços de quibe, totalizando mais de $900 \mathrm{mg}$ de sódio e ninguém consumiu mais de uma porção de farofa, apresentando menor risco à saúde.

A partir do calculo teor de sódio das preparações, foram modificadas as receita para que se adequassem $200 \mathrm{mg}$ de sódio por porção, pois apenas o feijão contribuiu em $66,49 \%$ do 
sódio recomendado para o almoço. A tabela 2 apresenta a composição nutricional antes e após a modificação.

Tabela 2 - Composição nutricional das amostras de Feijão Tropeiro

\begin{tabular}{lcc}
\hline & Padrão (105g) & Modificado (105g) \\
\hline VET (por porção) & $211,71 \mathrm{Kcal}$ & $164,09 \mathrm{Kcal}$ \\
\% PTN & 12,92 & 15,66 \\
\% CHO & 62,62 & 75,54 \\
\% LIP & 24,45 & 8,78 \\
\hline Na (mg) & $\mathbf{5 3 1 , 9 5}$ & $\mathbf{2 1 7 , 6 7}$ \\
\hline
\end{tabular}

As modificações foram as seguintes: redução de 30 gramas de sal para 10 gramas, adição de 20 gramas de cebolinha, aumento de 50 gramas de cebola para dar mais sabor ao prato, a retirada do óleo e aumento da couve para 230 gramas para aumentar o rendimento da preparação e ter menos sódio por porção. O aumento da couve pode ter contribuído para o aumento do carboidrato e da proteína. Já a redução do teor lipídico deve-se à retirada do óleo.

O objetivo de obter $200 \mathrm{mg}$ não foi alcançado, estando, pois, muito próximo da recomendação. Não foi possível excluir maior quantidade de sal, pois comprometeria o sabor da preparação. Outra sugestão é colocar o feijão tropeiro em dias que existam preparações com menor teor de sódio.

A tabela 3 demonstra a composição nutricional da farofa de ovos antes e após as modificações.

Tabela 3 - Composição Nutricional das amostras de farofa com ovos

\begin{tabular}{l|cc}
\hline & Padrão (50g) & Modificado (50g) \\
\hline VET (por porção) & 209,74 Kcal & $205,53 \mathrm{Kcal}$ \\
\% PTN & 5,07 & 3,95 \\
\% CHO & 66,19 & 67,30 \\
\% LIP & 28,73 & 28,73 \\
\hline Na (mg) & $\mathbf{3 7 9 , 8 4}$ & $\mathbf{2 0 0 , 6 9}$ \\
\hline
\end{tabular}


Nesta preparação, foi necessário apenas retirar o caldo de bacon para alcançar a recomendação inferida neste trabalho (200mg de sódio) por ser um produto com alto teor de sódio, com isso não foi preciso reduzir o sal. Nota-se, ao compará-las, que, com as modificações não houve alterações na composição nutricional.

A Tabela 4 mostra a composição nutricional do quibe recheado, que apesar representar apenas 37,82\% das recomendações para o almoço, é preparado com alguns ingredientes com alto teor de sódio.

Tabela 4 - Quibe assado recheado com molho branco

\begin{tabular}{l|cc}
\hline & Padrão (70g) & Modificado (70g) \\
\hline VET (por porção) & 106,77 Kcal & $150,96 \mathrm{Kcal}$ \\
\% PTN & 59,41 & 52,99 \\
\% CH0 & 18,08 & 17,02 \\
\% LIP & 22,50 & 29,98 \\
\hline Na (mg) & $\mathbf{3 0 2 , 5 9}$ & $\mathbf{1 9 6 , 5 4}$ \\
\hline
\end{tabular}

Foi preciso retirar o molho de tomate industrializado. O molho branco foi feito com 100 gramas de margarina, 60 gramas de farinha de trigo, noz moscada, pimenta do reino e a mesma quantidade de queijo prato para permanecer o sabor original da receita.

A adição de farinha de trigo e o aumento de margarina podem ter contribuído para o aumento das calorias e do teor lipídico respectivamente. Só a retirada do molho foi suficiente para reduzir pela metade o teor de sódio, que foi compensado por noz moscada e pimenta do reino para conferir sabor à receita.

Foi aplicado um teste de Análise Sensorial com 20 clientes, pois no local circulam em média 100 pessoas, representando $20 \%$ da clientela diária do estabelecimento. Cada cliente degustou a preparação original e depois a modificada, fornecendo suas notas conforme demonstrado no formulário desenvolvido. Após sua realização, para verificar a aceitabilidade dos pratos com baixo teor de sódio, os seguintes resultados foram obtidos (Tabelas 5,6 e7). 
Tabela 5 - Médias de aceitação da farofa com ovo

\section{Padrão Modificado}

\begin{tabular}{lll}
\hline Avaliação geral & 6,0 & 6,5 \\
Sabor & 5,5 & 6,5 \\
Cor & 5,5 & 6,0 \\
Odor & 5,5 & 6,0 \\
\hline
\end{tabular}

Após as modificações, em relação ao atributo odor, as pessoas aceitaram mais a preparação modificada, esse fato pode ser atribuído à ausência do caldo de bacon, que tem odor característico e não é naturalmente encontrado em farofa de ovos. Todos os outros itens foram melhor avaliados na farofa modificada, demonstrando que a redução de sódio de 52,83\% melhorando o sabor da preparação..

Tabela 6 - Médias de aceitação do Feijão Tropeiro

\begin{tabular}{l|cc}
\hline & Padrão & Modificado \\
\hline Avaliação geral & 6,15 & 7,0 \\
Sabor & 6,3 & 7,0 \\
Cor & 6,35 & 7,0 \\
Odor & 7,0 & 7,0 \\
\hline
\end{tabular}

O fato de ter reduzido o sal e compensá-lo com mais cebola e cebolinha para conferir sabor, pode ter contribuído para melhor aceitação da preparação. O acréscimo de couve melhorou a aparência do produto, o que influencia positivamente na aceitabilidade da preparação. Ressaltase que as duas preparações, original e modificada, foram executadas pelo mesmo cozinheiro que seguiu a ficha técnica de forma correta.

Tabela 7 - Médias de aceitação do Quibe Assado.

\begin{tabular}{lcc}
\hline & Padrão & Modificado \\
\hline Avaliação geral & 5,9 & 6.5 \\
Sabor & 5,85 & 6,5 \\
Cor & 6 & 6,5 \\
Odor & 5,5 & 6,0 \\
\hline
\end{tabular}


No geral, o quibe foi bem aceito pelos indivíduos, o fato de ter trocado o molho branco feito com amido de milho pelo molho Bechamel, pode ter sido responsável pela melhor aceitação, pois deixou a preparação mais leve e saborosa contribuindo positivamente para uma melhor aceitação. Apesar de seu odor forte notado pela maioria das pessoas.

As tabelas 8, 9 e 10 representam a comparação dos percentuais de aceitação antes e depois das modificações de cada prato escolhido para cada quesito avaliado. Esse percentual foi considerado para notas superiores a 5 .

Tabela 8 - Percentual de aceitação da farofa com ovos

\begin{tabular}{lcc}
\hline & Padrão & Modificado \\
\hline Avaliação geral & $100 \%$ & $100 \%$ \\
Sabor & $100 \%$ & $100 \%$ \\
Cor & $85 \%$ & $95 \%$ \\
Odor & $70 \%$ & $90 \%$ \\
\hline
\end{tabular}

Alguns indivíduos relataram que a farofa ficou um pouco seca, mas não afetou na aceitabilidade. Como pode se observar, a retirada do caldo de bacon proporcionou melhora no percentual de aceitação para cor e odor. 
Tabela 9 - Percentual de aceitação do feijão tropeiro

\begin{tabular}{lcc}
\hline & Padrão & Modificado \\
\hline Avaliação geral & $100 \%$ & $100 \%$ \\
Sabor & $100 \%$ & $100 \%$ \\
Cor & $95 \%$ & $100 \%$ \\
Odor & $90 \%$ & $100 \%$ \\
\hline
\end{tabular}

O feijão foi bem aceito por todos os indivíduos que participaram da pesquisa, mostrando que a cebolinha e a cebola contribuem positivamente, acrescentando melhor sabor à preparação. Além do que a cebola possui propriedade antiinflamatória, antimicrobiana e é bronco dilatadora, sendo utilizada no tratamento de pneumonia, febre e outras causadas por microorganismos, podendo ser usada como coadjuvante terapêutico (TORRES, 2005). Seu consumo em grandes quantidades contribui na prevenção da hipertensão arterial sistêmica.

Tabela 10 - Percentual de aceitação do quibe assado

\begin{tabular}{lcc}
\hline & Padrão & Modificado \\
\hline Avaliação geral & $95 \%$ & $100 \%$ \\
Sabor & $95 \%$ & $100 \%$ \\
Cor & $95 \%$ & $100 \%$ \\
Odor & $75 \%$ & $80 \%$ \\
\hline
\end{tabular}

A noz moscada e a pimenta do reino conferiram um novo sabor ao prato, porém a ausência do sal foi notada por algumas pessoas. Para o odor, algumas pessoas relataram que não o sentiram no quibe e por isso não deram nota.

A tabela a baixo mostra o percentual de sódio que foi reduzido em cada preparação.

Tabela 11 - Percentual de redução de sódio das preparações em relação às preparações originais.

\begin{tabular}{l|c}
\hline Preparação & \% de redução \\
\hline Farofa com ovos & 53,83 \\
Feijão tropeiro & 40,91 \\
Quibe assado & 64,95 \\
\hline
\end{tabular}


Nota-se que a preparação em que foi necessário o maior percentual de redução foi o quibe, por ser preparada com produto industrializado rico em sódio (molho de tomate).

Em virtude da experiência e da cautela do cozinheiro que executou as receitas, foi difícil encontrar preparações nas quais contivesse, em sua composição, alto teor de sódio. Para encontrá-las foi necessário realizar várias fichas técnicas para, então, poder modificá-las. Além disso, a modificação do quibe foi bem aceita pela clientela, tanto que fará parte do cardápio semanal do estabelecimento. 


\section{CONCLUSÃO}

Produto sempre apreciado na gastronomia, o sal faz parte de quase todas as receitas culinárias para conferir sabor aos diversos pratos e ressaltar o paladar de outros ingredientes, além de preservar os alimentos, tendo função antibactericida (RODRIGUES, 2005).

Em restaurantes, o sal deve ser utilizado pelos cozinheiros com moderação, pois o excesso pode acarretar danos à saúde do cliente, como a hipertensão arterial, exposta nesse trabalho. Além de contar com a presença do saleiro sobre a mesa, sempre disponível ao cliente, tornando-se mais difícil controlar a quantidade de sódio consumida. E para que o cozinheiro controle o sódio de cada preparação, o mesmo deve seguir corretamente a Ficha Técnica de Preparação, pois nela o nutricionista calcula a quantidade de sódio de cada porção.

De acordo com a presente pesquisa, percebe-se que o sal e os produtos industrializados com alto teor de sódio são ingredientes fundamentais em qualquer receita, mas que podem ser substituídos ou compensados por uma variedade de temperos, que tenham a mesma função do sal, de conferir sabor, além de dar aroma aos pratos e terem baixas calorias. Nessa pesquisa, foi testada apenas a substituição do sal pela cebola e cebolinha no feijão tropeiro, o que também conferiu sabor à preparação.

A partir dos resultados, nota-se que a modificação do feijão tropeiro foi a preparação mais aceita entre as pessoas que participaram da pesquisa, por ter sido compensado o sal com mais cebola e cebolinha, melhorando seu sabor e sua aparência ao acrescentar mais couve.

Foi necessário reduzir $53,83 \%$ de sódio por porção da farofa em relação à receita original, $40,91 \%$ de sódio do feijão tropeiro e $64,95 \%$ do quibe assado, sendo a preparação na qual foi preciso maior redução por haver sido preparada com extrato de tomate, que é um ingrediente industrializado rico em sódio. Assim, foi necessário apenas retirar o extrato de tomate para atingir a recomendação inferida no trabalho.

A ausência do sal nas preparações é bem notada pelas pessoas, pois o paladar é muito individual. No entanto nesse estudo os clientes não perceberam a redução, pois a mesma foi gradual. Para que as pessoas acostumem com a ausência do sódio, basta retirá-lo gradualmente ou substituí-lo por ervas. Isso é uma questão de mudança de hábito e treino do paladar, que com o tempo se adapta. 
ANEXO 1

\section{FICHA DE PREPARAÇÃO}

NOME DA PREPARAÇÃO:

\begin{tabular}{|c|c|c|c|c|c|c|}
\hline INGREDIENTES & $\begin{array}{c}\text { Peso } \\
\text { Bruto }\end{array}$ & $\begin{array}{c}\text { Peso } \\
\text { líquido }\end{array}$ & FC & $\begin{array}{c}\text { Per } \\
\text { capita }\end{array}$ & $\begin{array}{c}\text { Custo } \\
\text { Individual }\end{array}$ & Modo de Preparo \\
\hline & & & & & & \\
\hline & & & & & & \\
\hline & & & & & & \\
\hline & & & & & & \\
\hline & & & & & & \\
\hline & & & & & & \\
\hline & & & & & & \\
\hline & & & & & & \\
\hline & & & & & & \\
\hline & & & & & & \\
\hline & & & & & & \\
\hline & & & & & & \\
\hline & & & & & & \\
\hline
\end{tabular}

VET total $=$

VET individual $=$

PTN

g

LIP

g

Kcal $\%$

CHO

g

Kcal $\%$
Fator de cocção/Fator de conversão: Índice de absorção:

Rendimento:

Porção: g

Porção (med. Caseira):

Densidade:

$\mathrm{Na}$ 
FICHA DE ANÁLISE DA PREPARAÇÃO

\begin{tabular}{|c|c|c|c|c|c|}
\hline ALIMENTOS & $\begin{array}{c}\text { Qtd } \\
\text { (g) }\end{array}$ & $\begin{array}{c}\text { CHO } \\
\text { (g) }\end{array}$ & $\begin{array}{c}\text { PTN } \\
\text { (g) }\end{array}$ & $\begin{array}{r}\text { LIP } \\
\text { (g) }\end{array}$ & NA \\
\hline & & & & & \\
\hline & & & & & \\
\hline & & & & & \\
\hline & & & & & \\
\hline & & & & & \\
\hline & & & & & \\
\hline & & & & & \\
\hline & & & & & \\
\hline & & & & & \\
\hline & & & & & \\
\hline & & & & & \\
\hline & & & & & \\
\hline & & & & & \\
\hline & & & & & \\
\hline & & & & & \\
\hline
\end{tabular}




\section{ANEXO 2 - TESTE DE ANÁLISE SENSORIAL}

\section{TESTE DE ANALISE SENSORIAL Amostra 1}

Sexo:

Idade:

Por favor, avalie o feijão tropeiro utilizando a escala abaixo para descrever o quanto você gostou ou desgostou do produto. Marque a posição da escala reflita seu julgamento.

Código da amostra:

(7) Gostei muitíssimo

( ) Avaliação geral do produto

(6) Gostei moderadamente

(5) Gostei ligeiramente

( ) Sabor

(4) Indiferente

( ) Cor

(3) Desgostei ligeiramente

( ) Odor

(2) Desgostei moderadamente

( ) Temperatura

(1) Desgostei muitíssimo

Comentários: 
ANEXO 3 - FICHA TÉCNICA DO FEIJÃO TROPEIRO ORIGINAL

\begin{tabular}{|l|l|l|l|l|l|l|l|l|}
\hline Ingredientes & PB (g) & PL(g) & FC & $\begin{array}{c}\text { Per } \\
\text { Capita }\end{array}$ & PTN(g) & CHO(g) & Lip.(g) & Na(mg) \\
\hline Feijão & 628 & 628 & 1,00 & 24,15 & 125,6 & 384,33 & 8,16 & 12,56 \\
\hline Calabresa & 200 & 190 & 1,05 & 7,3 & 30,59 & - & 33,44 & 2090 \\
\hline Óleo & 105 & 105 & 1,00 & 4,03 & - & - & 105 & - \\
\hline Alho & 45 & 35 & 1,28 & 1,34 & 4,25 & 22,25 & 0,25 & 1,75 \\
\hline Cebola & 165 & 155 & 1,06 & 5,96 & 2,63 & 13,97 & 0,15 & 1,55 \\
\hline Sal & 30 & 30 & 1,00 & 1,15 & - & - & - & 11627,4 \\
\hline $\begin{array}{l}\text { Farinha de } \\
\text { mandioca }\end{array}$ & 500 & 500 & 1,00 & 19,23 & 8,5 & 432 & 1,5 & 5 \\
\hline Couve limpa & 215 & 215 & 1,00 & 8,26 & 6,23 & 9,24 & 1,07 & 92,45 \\
\hline Água & 1000 & 1000 & 1,00 & 38,46 & - & - & - & - \\
\hline
\end{tabular}

\section{Modo de preparo}

- Numa panela de pressão, cozinhar o feijão em 1lito de água r por 30 minutos e reservar.

- Em outra panela, refogar o óleo, a cebola, o alho e a calabresa em fogo médio por 10 minutos.

- Acrescentar o feijão cozido, a farinha e a couve e o sal.

- Mexer até agregar todos os ingredientes por 3 minutos em fogo médio

- Desligar o fogo e servir.

VET (Total): 5504,52Kcal

VET (individual): 211,71 Kcal

CHO: $3447,16 \mathrm{Kcal}$ - 62,62\%

PTN 711,2 Kcal - 12,92\%

LIP: $1346,16 \mathrm{Kcal}-24,45 \%$

Na: 531,95 mg per capita
Rendimento: $2780 \mathrm{~g}$

Porção: $105 \mathrm{~g}$

Rendimento (medida caseira) 1 escumadeira

$\mathbf{N}^{\text {o }}$ de porções: 26

Fcy:0,97 
ANEXO 4 - FICHA DE PREPARAÇÃO DE QUIBE ASSADO COM MOLHO BRANCO ORIGINAL

\begin{tabular}{|c|c|c|c|c|c|c|c|c|}
\hline Ingredientes & PB (g) & PL(g) & FC & $\begin{array}{c}\text { Per } \\
\text { Capita }\end{array}$ & PTN(g) & CHO(g) & Lip.(g) & $\mathrm{Na}(\mathrm{mg})$ \\
\hline $\begin{array}{l}\text { Trigo para } \\
\text { quibe }\end{array}$ & 500 & 500 & 1,00 & 9,26 & 625 & 150 & - & 190 \\
\hline Água & 1000 & 1000 & 1,00 & 18,51 & - & - & - & - \\
\hline Carne moída & 1000 & 1000 & 1,00 & 18,51 & 194 & - & 59 & 490 \\
\hline $\begin{array}{l}\text { Molho de } \\
\text { Tomate }\end{array}$ & 230 & 230 & 1,00 & 4,25 & 3,22 & 17,71 & 2,07 & 961,4 \\
\hline $\begin{array}{l}\text { Pimenta do } \\
\text { reino }\end{array}$ & 3 & 3 & 1,00 & 0,05 & 0,32 & 1,94 & 0,09 & 1,32 \\
\hline $\begin{array}{l}\text { Hortelã } \\
\text { limpo }\end{array}$ & 20 & 20 & 1,00 & 0,37 & 0,76 & 1,06 & 0,14 & 1 \\
\hline Sal & 15 & 15 & 1,00 & 0,27 & - & - & - & 5813,7 \\
\hline $\begin{array}{l}\text { Alho } \\
\text { descascado }\end{array}$ & 35 & 35 & 1,00 & 0,64 & 4,25 & 22,25 & 0,25 & 1,75 \\
\hline Óleo & 20 & 20 & 1,00 & 0,37 & - & - & 20 & - \\
\hline Cebola & 165 & 150 & 1,1 & 2,7 & 1,96 & 10,23 & 0,11 & 1,5 \\
\hline $\begin{array}{l}\text { Cheiro verde } \\
\text { limpo }\end{array}$ & 40 & 40 & 1,00 & 0,74 & 1,32 & 2,8 & 0,24 & 0,8 \\
\hline $\begin{array}{l}\text { Leite } \\
\text { integral }\end{array}$ & 800 & 800 & 1,00 & 14,81 & 24 & 36 & 36 & 512 \\
\hline $\begin{array}{l}\text { Margarina } \\
\text { com Sal }\end{array}$ & 15 & 15 & 1,00 & 0,27 & 0,06 & 0,015 & 12,36 & 134,25 \\
\hline Sal & 20 & 20 & 1,00 & 0,37 & - & - & - & 7751,6 \\
\hline $\begin{array}{l}\text { Amido de } \\
\text { milho }\end{array}$ & 20 & 20 & 1,00 & 0,37 & 0,052 & 18,6 & 0,01 & - \\
\hline Queijo prato & 50 & 50 & 1,00 & 0,92 & 1,5 & 0 & 13,9 & 482,5 \\
\hline
\end{tabular}




\section{Modo de preparo}

- Deixar o trigo para quibe de molho em 1 litro de água por 1 hora sob refrigeração.

- Numa panela de pressão, refogar o óleo e a cebola em fogo médio por 3 minutos.

- Acrescentar na panela de pressão a carne, o sal, a pimenta e cozinhar na pressão por 10 minutos.

- Acrescentar o molho de tomate o trigo para quibe, a hortelã, o cheiro-verde e reservar.

\section{Molho branco:}

- Numa frigideira, derreter a margarina, acrescentar o leite e o amido de milho dissolvido em $30 \mathrm{ml}$ de leite e mexer por aproximadamente 2 minutos em fogo médio por 3 minutos.

- Colocar o sal, e por último colocar o queijo.

\section{Montagem}

- Num tabuleiro, fazer uma camada de quibe, uma de molho branco e por último outra de quibe.

- Levar ao forno por 30 minutos e servir.

VET (total)5765,71 Kcal

VET (individual): 106,77 Kcal

CHO: $1042,42 \mathrm{Kcal}$ - 18,08\%

PTN: $3425,76 \mathrm{Kcal}-59,41 \%$

LIP: $1297,53 \mathrm{Kcal}-22,50 \%$

Na: $302,59 \mathrm{mg}$ per capita
Rendimento: $3755 \mathrm{~g}$

Porção: $70 \mathrm{~g}$

$N^{0}$ de porções: 54

FCY : 0,95 do quibe pronto e montado

Rendimento (medida caseira): 1 pedaço médio 


\section{ANEXO 5 - FICHA TÉCNICA DA FAROFA COM OVOS ORIGINAL}

\begin{tabular}{|l|l|l|l|l|l|l|l|l|}
\hline Ingredientes & PB (g) & PL(g) & FC & $\begin{array}{l}\text { Per } \\
\text { Capita }\end{array}$ & PTN(g) & CHO(g) & Lip.(g) & Na(mg) \\
\hline $\begin{array}{l}\text { Farinha de } \\
\text { mandioca }\end{array}$ & 1000 & 1000 & 1,0 & 38,46 & 16 & 879 & 3 & 10 \\
\hline Cebola & 160 & 150 & 1,06 & 5,76 & 2,55 & 13,45 & 0,15 & 15 \\
\hline Óleo & 100 & 100 & 1 & 3,84 & - & - & 100 & - \\
\hline Bacon limpo & 40 & 40 & 1,00 & 1,53 & - & - & 39,43 & 218,08 \\
\hline $\begin{array}{l}\text { Caldo de } \\
\text { Bacon }\end{array}$ & 21 & 21 & 1,00 & 0,80 & 16,38 & 3,17 & 3,48 & 4657,8 \\
\hline Sal & 10 & 10 & 1,00 & 0,38 & - & - & - & 3875.8 \\
\hline Ovo & 271 & 250 & 1,08 & 9,61 & 33,25 & 4 & 22,25 & 560 \\
\hline $\begin{array}{l}\text { Cheiro-verde } \\
\text { limpo }\end{array}$ & 20 & 20 & 1,00 & 0,76 & 0,66 & 1,14 & 0,12 & 0,4 \\
\hline Azeitona & 60 & 40 & 1,5 & 1,53 & 0,36 & 1,64 & 5,68 & 538,8 \\
\hline
\end{tabular}

\section{Modo de Preparo}

1. Numa frigideira, colocar o óleo, a cebola e levar ao fogo médio por 3 minutos.

2. Acrescentar o bacon, deixar fritar por 3 minutos em fogo médio e acrescentar o caldo de bacon e os ovos por 3 minutos.

3. Colocar a farinha, e mexer até agregar todos os ingredientes.

4. Acrescentar o sal

5. Desligar o fogo e salpicar o cheiro-verde

VET (Total): 5453,39Kcal

VET (Individual): 209,74 Kcal

CHO: $3609,6 \mathrm{Kcal}-66,19 \%$

LIP: $1566,99 \mathrm{Kcal}-28,73 \%$

PTN: $276,8 \mathrm{Kcal}-5,07 \%$

\section{Rendimento: $1290 \mathrm{~g}$}

Porção: $50 \mathrm{~g}$

Rendimento (medida caseira): 1 concha (pequena)

$\mathbf{N}^{\mathbf{0}}$ de porções: 26

FCY: 0,79

Na: 379,84mg per capita 


\section{ANEXOS 6 - FICHAS TÉCNICA DO QUIBE ASSADO RECHEADO COM MOLHO BRANCO (MODIFICADA)}

\begin{tabular}{|c|c|c|c|c|c|c|c|c|}
\hline Ingredientes & PB (g) & PL (g) & FC & $\begin{array}{c}\text { Per } \\
\text { Capita }\end{array}$ & PTN(g) & CHO(g) & Lip.(g) & $\mathrm{Na(mg)}$ \\
\hline $\begin{array}{l}\text { Trigo para } \\
\text { quibe }\end{array}$ & 500 & 500 & 1,00 & 11,62 & 625 & 150 & - & 190 \\
\hline Água & 1000 & 1000 & 1,00 & 23,25 & - & - & - & - \\
\hline Carne moída & 1000 & 1000 & 1,00 & 23,25 & 194 & - & 59 & 490 \\
\hline $\begin{array}{l}\text { Pimenta do } \\
\text { reino }\end{array}$ & $3 g$ & $3 g$ & 1,00 & 0,06 & 0,32 & 1,94 & 0,09 & 1,32 \\
\hline $\begin{array}{l}\text { Hortelã } \\
\text { limpa }\end{array}$ & $20 \mathrm{~g}$ & $20 \mathrm{~g}$ & 1,00 & 0,046 & 0,76 & 1,06 & 0,14 & 1 \\
\hline Sal & $15 \mathrm{~g}$ & 15 & 1,00 & 0,34 & - & - & - & 5813,7 \\
\hline $\begin{array}{l}\text { Alho } \\
\text { descascado }\end{array}$ & $35 \mathrm{~g}$ & $35 \mathrm{~g}$ & 1,00 & 0,81 & 4,25 & 22,25 & 0,25 & 1,75 \\
\hline Óleo & 20 & 20 & 1,00 & 0,46 & - & - & 20 & - \\
\hline Cebola & 165 & 150 & 1,1 & 3,48 & 1,96 & 10,23 & 0,11 & 1,5 \\
\hline $\begin{array}{l}\text { Cheiro verde } \\
\text { limpo }\end{array}$ & $40 \mathrm{~g}$ & $40 \mathrm{~g}$ & 1,00 & 0,93 & 1,32 & 2,8 & 0,24 & 0,8 \\
\hline $\begin{array}{l}\text { Leite } \\
\text { integral }\end{array}$ & 800 & 800 & 1,00 & 18,60 & 24 & 36 & 36 & 512 \\
\hline $\begin{array}{l}\text { Margarina } \\
\text { com Sal }\end{array}$ & 100 & 100 & 1,00 & 2,32 & 0,10 & 0,10 & 82,00 & 894 \\
\hline $\begin{array}{l}\text { Farinha de } \\
\text { trigo }\end{array}$ & 60 & 60 & 1,00 & 1,39 & 5,88 & 45,05 & 0,84 & 60 \\
\hline $\begin{array}{l}\text { Noz } \\
\text { moscada }\end{array}$ & 10 & 10 & 1,00 & 0,23 & 0,58 & 4,93 & 3,63 & 1,62 \\
\hline $\begin{array}{l}\text { Pimenta do } \\
\text { reino }\end{array}$ & 3 & 3 & 1,00 & 0,06 & 0,32 & 1,9 & 0,09 & 1,32 \\
\hline Queijo prato & 50 & 50 & 1,00 & 1,16 & 1,5 & 0 & 13,9 & 482,5 \\
\hline
\end{tabular}




\section{Modo de preparo}

- Deixar o trigo para quibe de molho em 1 litro de água por 1 hora

- Numa panela de pressão, refogar o óleo, o alho amassado e a cebola em fogo médio por 3 minutos.

- Na panela de pressão, acrescentar a carne, o sal, a pimenta e cozinhar na pressão por 10 minutos.

- Acrescentar o molho de tomate, o trigo para quibe, a hortelã, e o cheiro-verde mexer e reservar.

\section{Molho Branco}

- Numa panela de fundo grosso, derreta a manteiga em fogo brando e polvilhe com a farinha. Deixe cozinhar, sem deixar ganhar cor, até aparecer à superfície uma espuma esbranquiçada e o preparado desagregar-se.

- Sempre em fogo baixo, despeje o leite frio de uma vez na panela e misture com um batedor ou uma colher de pau até que os ingredientes se incorporem Obs: caso prefira usar o leite morno, coloque-o aos poucos.

- Coloque o sal e a pimenta do reino;

- Deixe cozinhar por uns 10 minutos, ou até obter um creme, mexendo sempre.

- Desligue o fogo, acerte o sal e acrescente a noz moscada, misturando bem.

\section{Montagem}

- Num tabuleiro, fazer uma camada de quibe, uma de molho branco e por último outra de quibe.

- Levar ao forno por 30 minutos e serva

VET (Total): 6491, 61Kcal

VET (individual): 150,96 Kcal

PTN: $3439,96 \mathrm{Kcal}-52,99 \%$

CHO: $1105,04 \mathrm{Kcal}-17,02 \%$

LIP: $1946,61 \mathrm{Kcal}-29,98 \%$

Na: $196,54 \mathrm{mg}$ per capita
Rendimento: $3002 \mathrm{~g}$

No de porções: 43

Porção: 70 gramas

Rendimento (medida caseira): 1 pedaço Méd.

FCY: 0,78 do quibe pronto e montado 
ANEXO 7- FICHA TÉCNICA DO FEIJÃO TROPEIRO (MODIFICADA)

\begin{tabular}{|l|l|l|l|l|l|l|l|l|}
\hline Ingredientes & PB (g) & PL (g) & FC & $\begin{array}{c}\text { Per } \\
\text { Capita }\end{array}$ & PTN(g) & CHO(g) & Lip.(g) & Na(mg) \\
\hline Feijão & 628 & 628 & 1,00 & 22,42 & 125,6 & 384,33 & 8,16 & 12,56 \\
\hline Calabresa & 190 & 190 & 1,00 & 6,78 & 30,59 & - & 33,44 & 2090 \\
\hline Alho & 35 & 35 & 1,00 & 1,25 & 4,25 & 22,25 & 0,25 & 1,75 \\
\hline Cebola & 250 & 200 & 1,06 & 7,14 & 3,4 & 17,8 & 0,2 & 2 \\
\hline Sal & 10 & 10 & 1,00 & 0,35 & - & - & - & 3875,8 \\
\hline $\begin{array}{l}\text { Farinha de } \\
\text { mandioca }\end{array}$ & 500 & 500 & 1,00 & 17,85 & 8,5 & 432 & 1,5 & 5 \\
\hline $\begin{array}{l}\text { Cebolinha } \\
\text { limpa }\end{array}$ & 20 & 20 & 1,00 & 0,71 & 0,38 & 0,68 & 0,08 & 0,4 \\
\hline Couve limpa & 250 & 250 & 1,00 & 8,92 & 7,23 & 10,73 & 1,23 & 107,5 \\
\hline Água & 1000 & 1000 & 1,0 & 35,71 & - & - & - & - \\
\hline
\end{tabular}

\section{Modo de preparo}

- Numa panela de pressão, cozinhar o feijão em 1 litro de água com sal por 30 minutos e reservar.

- Em outra panela em fogo médio, fritar a calabresa até soltar sua própria gordura e desprezá-la. Em seguida, colocar o alho a cebola.

- Acrescentar o feijão cozido, a farinha e a couve;

- Mexer até agregar todos os ingredientes por 3 minutos em fogo médio

- Salpicar a cebolinha

- Desligar o fogo e servir.

VET (Total): 4594,70 Kcal

VET (individual): 164,09 Kcal

PTN: $719,80 \mathrm{Kcal}-15,66 \%$

CHO: $3471,16 \mathrm{Kcal}-75,54 \%$

LIP: 403,77 Kcal - 8,78\%

Na: $217,67 \mathrm{mg}$ per capita
Rendimento: $3000 \mathrm{~g}$

Porção: $105 \mathrm{~g}$

Rendimento (medida caseira) 1 escumadeira

FCY: 1, 05

$\mathbf{N}^{0}$ de porções: 28 
ANEXO 8 - FICHA TÉCNICA DA FAROFA DE OVOS (MODIFICADA)

\begin{tabular}{|l|l|l|l|l|l|l|l|l|}
\hline Ingredientes & PB(g) & PL(g) & FC & $\begin{array}{l}\text { Per } \\
\text { Capita }\end{array}$ & PTNg) & CHO(g) & Lip.(g) & Na(mg) \\
\hline $\begin{array}{l}\text { Farinha de } \\
\text { mandioca }\end{array}$ & 1000 & 1000 & 1,0 & 38,43 & 16 & 879 & 3 & 10 \\
\hline Cebola & 160 & 150 & 1,06 & 5,76 & 2,55 & 13,45 & 0,15 & 15 \\
\hline Óleo & 100 & 100 & 1 & 3,84 & - & - & 100 & - \\
\hline Bacon limpo & 40 & 40 & 1,00 & 1,53 & - & - & 39,43 & 218,08 \\
\hline Sal & 10 & 10 & 1,00 & 0.38 & - & - & - & 3875.8 \\
\hline Ovo & 271 & 250 & 1,08 & 9,61 & 33,25 & 4 & 22,25 & 560 \\
\hline $\begin{array}{l}\text { Cheiro-verde } \\
\text { limpo }\end{array}$ & 20 & 20 & 1,00 & 0,76 & 0,66 & 1,14 & 0,12 & 0,4 \\
\hline Azeitona & 60 & 40 & 1,5 & 1,53 & 0,36 & 1,64 & 5,68 & 538,8 \\
\hline
\end{tabular}

\section{Modo de Preparo}

6. Numa frigideira, colocar o óleo, a cebola e levar ao fogo médio por 3 minutos.

7. Acrescentar o bacon, deixar fritar por 3 minutos em fogo médio e acrescentar os ovos até cozinhá-los.

8. Colocar a farinha, e mexer até agregar todos os ingredientes.

9. Acrescentar o sal

10. Desligar o fogo e salpicar o cheiro-verde

VET (Total): 5343, $87 \mathrm{Kcal}$

VET (individual): 205,53 Kcal

PTN: $211,28 \mathrm{Kcal}-3,95 \% \%$

CHO: $3596,92 \mathrm{Kcal}-67,30 \%$

LIP: $1535,67 \mathrm{Kcal}-28,73 \%$

Na: $186,36 \mathrm{mg}$ per capita
Rendimento: $1290 \mathrm{~g}$

Porção: $50 \mathrm{~g}$

Rendimento (méd caseira): 1 concha (pequena)

$\mathbf{N}^{\mathbf{0}}$ de porções: 26

FCY: 0,80 


\section{Bibliografia}

AKUTSU, R. de C. et al. A ficha técnica de preparação como instrumento de qualidade na produção de refeições. Revista de Nutrição. vol.18. n². p.277-279.março, 2005

AMODEO, C. Hipertensão Arterial Sistêmica: Estratificando as Metas Terapêuticas Nutrição Profissional.vol.2. $\mathrm{n}^{\circ}$ 9. p. 15-18. abril, 2006.

ANDREO, D.; JORGE, N. Antioxidantes naturais: Técnicas de extração. Ver. De tecnologia dos alimentos. vol. 24. n². p. 319-327. jul/dez, 2006

ANGELO, P. M.; J.N. Compostos fenólicos em Alimentos- Uma breve revisão. Rev Inst Adolfo Lutz. vol.66. $n^{\circ} 1$. p. 232-240. janeiro, 2007

ARTHUR, C. G. M. D.; JOHN, E. H. PH. D. Tratado de Fisiologia Médica 10ªed. Editora Guanabara, 2002.

BRASIL. Ministério da Saúde. Secretaria de Atenção á Saúde. Guia Alimentar para a população brasileira: promovendo alimentação. Brasília: Ministério da Saúde; 2006.

CADE, N. V. A teoria de déficit de autocuidado de ordem, aplicadas a hipertensas. Revista Latino- am Enfermagem . v. 9 . nº. 3. p. 43-50. São Paulo. Maio, 2002.

CASTRO, M. E.; ROLIM, M. O.; MAURICIO, T. E. Prevenção da hipertensão e sua relação com estilo de vida de trabalhadores. Acta Paul Enfermagem.v.18.nº2. p.184-189. Fortaleza, 2006

COSTA, da Y. R.; Fagundes, R. L. M. Uso dos Alimentos Funcionais na Alimentação. Ver, de higiene Alimentar.vol. 17 .nº108. p.42-47. maio, 203

CUPPARI, L. Nutrição Clínica - Guia de Nutrição. 2 ed. Barueri-SP. Editora Manole, 2005.

DALTEPIANE, B. L.; BÓS, G. J. A.; O uso de condimentos na dieta em um grupo de hipertensos: estudo de intervenção randomizado, Revista Brasileira de Nutrição. v.22. $n^{\circ}$.4. p. 286- 297. Rio grande do Sul, 2007.

DULCE. Sal. história, cultura e gastronomia portuguesa. Disponível em:

http://dulcerodrigues.info/educa/pt/historia_sal_pt.html

FONSECA, M. T. Ficha técnica de preparação para restaurantes. Disponível em: http://www.mercadogastronomico.com.br/nosso-cotidiano/ficha-tecnica-para-

restaurantes.html Acesso em: 20/05/2008

GALVÃO, R.; JR, K.O. Hipertensão no paciente obeso. Revista Brasileira de Hipertensão. v.9. $n^{\circ} .3$. p.262-267. julho/setembro, 2002. 
GUERRA, A. M. N. de M. et al.Plantas medicinais e hortaliças usadas para cura de doenças em residências da cidade de Mossoró- RN. Revista verde de agroecologia e desenvolvimento sustentável.vol. 2 nº p. 70-77. jan/julho-2007

GUS, M. Que valores devem ser adotados como limites de normalidade na monitorização Ambulatorial da Pressão Arterial.Arquivo Brasileiro de Cardiologia.v. 85. nº3.p.212-214. setembro, 2005

JR, M. D., et al. Diretriz para hipertensão Arterial da Sociedade Brasileira de Nefrologia e Cardiologia: Abordagem geral. Jornal Brasileiro de Nefrologia. v.25. nº.1.p.51-5. fevereiro, 2002.

JR, H. de C.C. Tratamento não-medicamentoso. In: III Consenso de hipertensão arterial. 1998.

. KRUMMEL, D., Nutrição na hipertensão In: Mahan, L.K; STRUMP, S. E., Alimentos, nutrição e dietoterapia. Roca. p. 571.

LINO, A. I. de A. et al Trabalho de Enfermagem no rastreamento da hipertensão arterial em crianças e adolescentes em uma escola da rede pública de Goiânia- Goiás . Revista Eletrônica de Enfermagem, v.06. nº 02. p. 298-302, 2004.

LOTAIF, L. A. D., et al. Efeito da suplementação de potássio através do sal de cozinha na hipertensão arterial primária leve e moderada. Jornal Brasileiro de Nefrologia . v.7. nº 4. p. 214-218, 1995.

MADIAS, N. E. O que você pode fazer para tratar a hipertensão. Rio de Janeiro, 1982.

MEDEIROS, M. A. Sal de cozinha - $\mathrm{NaCl}$, ou o quê? Disponível em : http://www.quiprocura.net/sal.htm Acesso em: 26/05/2008.

SANTOS, Elissandra Ribeiro, Fatores de risco de hipertensão arterial na infầncia e na adolescência.[Monografia] Universidades Católicas de Brasília, 2005.

SANTOS, Z. M. de S. A.; SILVA. R. M. Hipertensão Arterial- Modelo de educação em Saúde para autocuidado. Fortaleza.Unifor, 2002

ZAITUNE, M. P. de A. et al. Hipertensão arterial em idosos: Prevalência, fatores de risco associados e práticas de controle no Município de Campinas. Caderno de Saúde Pública. v.22. nº 2. p. 285-294. São Paulo. fevereiro, 2006. 